\title{
PATRIMÔNIO E MEMÓRIA: DA IMPOSIÇÃO DE IDENTIDADES À POTENCIALIZAÇĀO DE ATOS COLETIVOS
}

Adalberto S. Santos adalbertosantos@ufba.br

\section{Introdução}

A Constituição de 1988 define no Artigo 216 que patrimônio cultural brasileiro se compõe de bens de natureza material e imaterial. Do texto constitucional, depreende-se que o patrimônio cultural brasileiro se compõe de bens culturais e esses últimos são referências aos testemunhos materiais e imateriais portadores de interesse cultural relevante. Apesar da imprecisão como vem sendo tratado, o professor português José de Melo Alexandrino (2009) aponta o aparecimento do termo "bens culturais" depois da Segunda Guerra Mundial, mais precisamente 
em 1954 na Convenção da UNESCO sobre a Proteção de Bens Culturais em Caso de Conflito Armado. O termo volta a reaparecer na Convenção sobre Importação, Exportação e Transferência Ilícita de Bens Culturais de 1970 e na Convenção do Patrimônio Mundial, Cultural e Natural de 1972, para, embora com sutis diferenças, ratificar uma concepção de bem cultural delineada em torno da noção de bens móveis ou imóveis relevantes.

Com o passar dos anos, a noção de bens culturais se constituiu na categoria jurídica que tem estruturado as políticas de patrimônio cultural e supõe, fundamentalmente, a presença de um valor ancorado num suporte. Tais suportes encerram duas dimensões: a primeira se define pelo caráter material das criações humanas e a segunda pelo caráter imaterial, simbólico dessas criações. Dessa forma, mesmo quando se ressalta a natureza material dos bens culturais não se pode esquecer que esses objetos são portadores de determinado(s) valor(es) que lhe dá(ão) sentido(s).

É justamente no suporte sobre o qual recai o valor que se encontram as bases que estruturam as políticas culturais nesse âmbito. Se o amparo do valor é corpóreo, tangível, diz-se que esse bem é material e para salvaguardá-lo foram criados estatutos jurídicos específicos. Se o valor se institui sem necessidade de mediação de objetos, ou seja, sem que sejam necessários objetos para representá-los, esse bem é imaterial ou intangível. Embora essa classificação tenha um caráter operacional que permite a instauração de políticas específicas, levando em consideração as dimensões dos bens culturais, não se pode tomá-la de modo absoluta, pois, na cultura, os aspectos matérias/tangíveis e imateriais/intangíveis formam unidade integrada na qual

[...] construção material, simbólica, significados e representações se constroem em diversidade e harmonia. A separação, assim, entre patrimônio material (que se 
tomba) e 'imaterial' (que se registra) é possível apenas para cumprir didatismos e burocracias. (MENEZES, 2009, p. 39)

Mas se a caracterização dos bens culturais vem apontando para uma falsa dicotomia entre as dimensões materiais e imateriais, a disseminação da noção de bens imateriais tem aprofundado uma vertente que, erroneamente, restringe essas características aos universos das culturas tradicionais populares e indígenas, sem atentar que a definição da dimensão de um bem cultural, material/ tangível ou imaterial/intangível, não se reporta a sua origem, mas o suporte sobre o qual se assentam os sentidos.

Dominique Poulot (2009) nos conduz nas trilhas dos imaginários que dotaram determinados bens culturais de tratamento especial, ressaltando dois aspectos que marcam a constituição de patrimônios culturais no ocidente: para o referido autor a noção de patrimônio se sustenta no caráter pedagógico e no reconhecimento de determinados bens como tesouro. Ao longo dos séculos, a noção de que determinados bens são tesouros que necessitam ser preservados e o caráter pedagógico que se inscreve na formulação dos princípios constitutivos dessa proteção dão sustentação à noção de patrimônio cultural.

É nos primórdios do cristianismo que se encontram as matizes do que hoje se denomina patrimônio cultural. Na Idade Média, o culto e a devoção a objetos sagrados, ou seja, a devoção às relíquias cristãs, introduziu a concepção de que tais tesouros simbolizavam a presença de memória associada à prática social da religião, justificando a necessidade de preservá-las em espaços definidos, sejam templos, tumbas ou locais sagrados.

A veneração a esses objetos fundou a noção de patrimônio e inscreveu os bens culturais no espaço de legitimação do poder, realçando o caráter pedagógico dessa prática simbólica. No en- 
tanto, afirma Lanari Bo (2003), gradativamente a necessidade de proteção e de veneração estendeu-se do espaço da igreja ao centro religioso da cidade, permitindo o florescimento da necessidade de eleição de objetos e lugares como instância de mediação entre as elites dominantes e seus súditos, e se inicialmente a noção de patrimônio estava atrelada à sua matriz religiosa, aos poucos evoluiu para considerações de ordem cultural: bibliotecas, arquivos, castelos, incluindo obras de arte.

Foi só a partir da Revolução Francesa que surgiram concepções que defendiam a necessidade de políticas públicas para preservar e valorizar os bens representativos da nação. A possibilidade de perda do patrimônio passou, ao mesmo tempo, a ser causa e o efeito das políticas de proteção legal. Fragmentos culturais salvaguardados da perda e da degradação materiais foram eleitos como pontos de contato com o passado, de modo a permitir que os modernos Estados-Nacionais se constituíssem como comunidades imaginadas nos moldes propostos por Benedict Anderson (2005). Mas foi a partir da segunda metade do século XX que o processo de consolidação da noção de patrimônio cultural se converteu em instrumentos legais de proteção de bens públicos, que passaram a serem merecedores de proteção, visando à sua transmissão para as gerações futuras. Por meio desses instrumentos, os Estados impuseram uma imagem da nação por meio daquilo que Manuel Castells (2002) denomina de identidade legitimadora e, em nome da nação, criaram estatutos jurídicos que definiram processos de seleção e proteção do patrimônio cultural nacional por meio de rituais bastante específicos, conduzidos por agentes com um perfil intelectual definido. $\mathrm{O}$ estatuto jurídico

[...] funciona como linguagem performativa de um modo bastante peculiar; não apenas definem direitos e deveres para o Estado e para os cidadãos como também inscreve 
no espaço social determinados ícones, figurações concretas e visíveis de valores que se quer transmitir e preservar. (FONSECA, 2005, p. 37)

As políticas de preservação passaram a ser propostas com intuito de atuarem, basicamente, na esfera simbólica, tendo como objetivo reforçar a identidade coletiva. Nesse ínterim, o conceito de patrimônio cultural, nas instâncias especializadas, passa a ser aplicado aos bens culturais que sofrem intermediação do Estado por meio de agentes autorizados e de práticas socialmente definidas e juridicamente regulamentadas, fixando-se sentidos e valores, priorizando-se uma determinada leitura:

seja a atribuição de valor histórico, enquanto testemunho de um determinado espaço/tempo vivido por determinados atores: seja de valor artístico, enquanto fonte de fruição estética [...], seja de valor etnográfico, enquanto documento de processos e organizações sociais diferenciados. (FONSECA, 2005, p. 42)

Se, no passado, a noção de patrimônio estava atrelada à veneração e, consequentemente, à Igreja, na contemporaneidade para se compreender o estágio da aplicação do conceito e o processo de conformação das políticas públicas de cultura, faz-se necessário entender as ações da UNESCO, na medida em que elas exemplificam os resultados da intensa evolução do conceito e das políticas daí decorrentes. Com o fim da Segunda Guerra Mundial, a noção de patrimônio cultural desempenhou papel preponderante na reconstrução do mundo, sendo a dimensão cultural incorporada ao Estatuto das Nações Unidas. A partir daí, a UNESCO tem produzido documentos orientadores para as políticas de seus Estados-Membros, estabelecendo as linhas mestras para a execução de políticas culturais e determinando as ações dos autorizados a fazerem a distinção entre o que pode subsistir e o que pode desaparecer. 
Documentos como a Convenção sobre a Salvaguarda do Patrimônio Mundial, Cultural e Natural de 1972, a Convenção para Salvaguarda do Patrimônio Cultural Imaterial de 2003 e a Convenção sobre a Proteção e Promoção da Diversidade das Expressões Culturais de 2005, entre outros, se constituíram como importantes documentos jurídicos no que tange à definição da preservação do patrimônio mundial, pois preveem a proteção de bens considerados de valor universal e excepcional por meio de procedimentos de inscrição na Lista de Patrimônio Cultural da Humanidade.

A revisão dos documentos produzidos pela UNESCO ao longo do século XX levou à percepção de três dimensões distintas para a promoção e proteção do patrimônio cultural dos povos e das nações, uma vez que tomava corpo a ideia de encontrar justificativas para a adoção de medidas financeiras que viabilizassem ações nos mais diversos âmbitos da cultura. Tais justificativas foram embasadas nas noções de desenvolvimento econômico e social, produzidas a partir dos anos 1960, viabilizando, primeiramente, políticas de proteção e promoção do patrimônio vinculadas às políticas de turismo, passando pelas políticas de habitação até, nos anos 1990, se poder formular justificativas culturais para a promoção e proteção de patrimônios, levando o Estado ampliar suas ações a âmbitos, até então, não atendidos. (SANTOS, 2011)

\section{Da memória nacional, a reflexão sobre a brasilidade}

$\mathrm{Na}$ cena brasileira, foram muitos os dispositivos acionados por diferentes gestões públicas para levar à sociedade ao imaginário moderno que, em nome da produção da memória nacional, 
pautaram suas ações em propósitos e estratégias articulados que protagonizaram uma narrativa totalizadora de povo enquanto unidade, como sujeito da nação. O itinerário que marca as políticas culturais no Brasil faz perceber como a tentativa de produzir uma memória nacional que servissem aos interesses legitimadores do regime imposto por Getulio Vargas, bem como pela Ditadura Militar que adentra a cena nacional em 1964, estiveram pautados nesse princípio.

A história das políticas culturais brasileira remete às ações de preservação desencadeadas pelo ministro Gustavo Capanema, ao qual estava subordinado o setor nacional da cultura durante o governo Getúlio Vargas e teve nas políticas para o patrimônio o seu nascimento. O Serviço do Patrimônio Histórico e Artístico Nacional (SPHAN) órgão criado em pleno Estado Novo pelo Decreto-Lei ${ }^{\circ}$ 25, de 30 de novembro de 1937, para levar a cabo uma política de patrimônio que visava à constituição da memória nacional por meio da preservação e da conservação do patrimônio material - instituiu a prática do tombamento como instrumento central da política de preservação. Para esse fim, foram criados quatro livros de tombo para a inscrição dos bens materiais, são eles: Tombo Arqueológico, Etnográfico e Paisagístico; Tombo Histórico; Tombo das Belas Artes e Tombo das Artes Aplicadas. O tombamento tem como principal objetivo a adequação de propriedade à função social. Através desse instrumento legal o Poder Público, no plano federal, declara que bens culturais de natureza material são portadores de características especiais, merecendo ser preservado em atendimento aos interesses da nação. (CUNHA, 2004) O estatuto do tombamento se manteve, até a elaboração do Programa Nacional do Patrimônio Imaterial (PNPI) em 2000, como o único instrumento legal disponível para outorga da condição de patrimônio cultural nacional. 
A ideia básica era a promoção do registro da nação, ou seja, era preciso tornar visível a face da nação brasileira, não mais a partir da incorporação de traços da natureza como no romantismo, mas através da identificação de tradição cultural que tivesse duração no tempo e visibilidade no espaço. (VELOSO, 1996) De posse dessa premissa, os intelectuais que compunham o SPHAN institucionalizaram um conjunto de práticas culturais voltadas para a preservação cultural, que durante mais de três décadas, privilegiaram a arquitetura colonial dos séculos XVI ao XVIII e que associou a noção de patrimônio aos bens materiais e a preservação à prática constituída de operações voltadas para seleção, proteção, guarda e conservação desses bens.

A celebração da antiguidade barroca se constitui na possibilidade de inscrição do passado no cotidiano, através do apelo ao memorável. A potencialização das referências ao passado barroco, que sobrevivia no cenário urbano de cidades coloniais brasileiras, instaurou a possibilidade de uma reflexão sobre brasilidade, pautada em elementos selecionados a partir da prática de tombamento, que dava sentido ao passado e ao mesmo tempo produzia uma "imagem" do presente. Fragmentos e restos do passado colonial brasileiro foram ressignificados para sustentar o ideário de uma cultura nacional coerente. (SEVERINO; SANTOS, 2010, p. 2)

Uma concepção da memória nacional, entendida como depósito passivo dos vestígios do passado que sobrevivem no presente, evocava a assimilação do passado tomando por base a transformação desses vestígios, mas ao mesmo tempo a ressignificação, ou seja, a produção de novos sentidos inerentes às práticas de preservação, provocava tensão entre a tradição barroca e as modernas tendências de preservação, causando certa estranheza na medida em que os vestígios, testemunhos de um passado, tinham que ser atualizados através das práticas de tombamento. 
No entanto, não se pode esquecer que a produção da memória nacional se constituiu num potente instrumento propiciador de reflexão sobre a brasilidade, revelando o caráter transformador das políticas de produção da memória nacional. As práticas adotadas pelo SPHAN, ao inaugurarem na cena brasileira a possibilidade de potencializar sentidos a partir da eleição de uma memória comum, constituíram-se em matriz de formas de pensar o futuro que marcaram as políticas de patrimônio por mais de três décadas. A instituição do projeto getulista de salvaguarda do patrimônio nacional instaurou uma forma de ação nesse campo, na medida em que vinculava a produção da memória nacional a uma atividade autorrepresentativa, essa, por sua vez, implicada na defesa de identidades e, consequentemente, na orientação da ação individual e coletiva. Nessa perspectiva, pode-se afirmar que as políticas de patrimônio, numa relação estreita com as políticas de produção da memória nacional, foram tomadas como elemento que atuariam como o "cimento" indispensável à coesão social necessária para emergência e sobrevivência dos regimes ditatoriais brasileiros.

Mas se o projeto inaugurado na Gestão Capanema revelou seu caráter transformador, paradoxalmente - ao ligar a reprodução da sociedade ao lastro de uma tradição cultural, conferindo sentido de permanência à sociedade brasileira a partir de sua herança europeia -, permitiu que determinados grupos traçassem suas origens e que garantissem seu reconhecimento enquanto formador da identidade nacional no decorrer do tempo, relegando as demais matrizes formadoras da identidade nacional ao esquecimento. Ao se privilegiar a fixação de certos sentidos, as ações adotadas integraram os mecanismos de controle social, revelando a produção da memória enquanto espaço de poder. No interior dos processos que constituíram a ação do SPHAN e posteriormente do IPHAN eram definidos o que nação deveria lembrar, mas, sobretudo, o que deveria esquecer. 
Sendo a memória uma forma de ação, a pretensão autorrepresentativa que orientou atuação do Estado no que se refere à produção da memória nacional se constituiu em ato de poder adotado pelos regimes ditatoriais brasileiros como mecanismo de controle. Através da produção da memória nacional, o Estado brasileiro idealizou um projeto que tinha como pressuposto a noção de que seria capaz de propor uma memória à coletividade.

Embora a atuação na produção social da memória coletiva e do esquecimento tenha sido uma das preocupações centrais dos regimes autoritários que dominaram a sociedade brasileira durante várias décadas, não se pode afirmar que apenas uma memória unificada e monolítica sobreviveu à ditadura Vargas e militar. E, por outro lado, também não se pode esquecer que as ações desencadeadas pelo SPHAN/IPHAN constituíram-se num importante passo para a consolidação de um campo de atuação no âmbito das políticas para o patrimônio e memória nacional.

\section{Do Estado guardião da memória, a síntese da nação}

Se no período getulista as políticas de patrimônio tinham como foco principal revelar a face da nação, os militares, por sua vez, vão empreender esforços no campo da produção da memória nacional para edificar uma imagem do Brasil homogêneo. Com esse intuito promovem uma reinterpretação da categoria de nacional, a partir da implantação de uma política cultural que buscava a concretização de uma identidade autenticamente brasileira. O governo militar adotou uma linha desenvolvimentista pautada na economia das diversas regiões brasileiras associada à preservação dos valores tradicionais, bem como do patrimônio nacional 
e viu, no turismo, a melhor alternativa econômica para conseguir atingir tais objetivos.

Uma das medidas mais significativa adotada pela Ditadura Militar que assume o controle do Estado em 1964 foi a criação, em 1966, do Conselho Federal de Cultura (CFC), órgão criado para ser o formulador da política nacional de cultura. Esse ato político enuncia a centralidade da cultura nos interesses dos novos gestores da cena nacional. Incumbido de formular a política nacional de cultura, o CFC se apropriou dos símbolos culturais e da memória nacional, tentando dotar o regime ditatorial da capacidade de impor uma memória coletiva a partir da produção de uma imagem sintética do ser nacional.

Iniciou-se um intenso processo de criação de novas instituições e órgãos culturais, bem como os primeiros esforços de gestação de programas e projetos que sustentariam uma política pública para a cultura no país. Vinculados ao Ministério da Educação e Cultura (MEC), ao longo do regime militar, nascem organismos culturais. Merece destaque, para efeito desse artigo, a criação do Centro Nacional de Referência Cultural (CNRC), em 1975. Ao mesmo tempo, redefiniu-se o papel do SPHAN, passando a chamar-se Instituto do Patrimônio Histórico e Artístico Nacional (IPHAN). Foi no seio desta especificidade simbólica da cultura, que o Estado implementou um rígido mecanismo de censura, marcando com punho forte a sua ingerência no domínio cultural. Porém, como chama atenção Renato Ortiz (2003), de forma similar ao modelo getulista, a censura militar vai intervir seletivamente na produção cultural, inibindo negativamente determinadas produções avessas aos princípios ideológicos dos militares, ao mesmo tempo em que estimulou a produção cultural que atendia aos interesses diretos do Estado e podia edificar uma imagem de seu povo. 
O fortalecimento da presença das indústrias culturais no circuito cultural brasileiro abre um novo espaço para a configuração da ideia de brasilidade. O entrelaçamento de eventos e relações sociais à distância, resultante de produções midiáticas eficazmente articuladas através das redes de televisão, atua para promover uma imagem homogênea e coerente da nação, projetando uma imagem do Brasil no cenário mundial e reforçando os laços identitários para o conjunto da população. Foi a época em que a promoção do samba, do futebol e das mulatas se constituíram em ícones que sintetizam o ideário de uma brasilidade mestiça, alegre e moleca. Os militares se apropriaram do mito fundador da brasilidade, ressaltando o aspecto da diversidade da cultura brasileira, compreendida como produto dos diversos matizes culturais que sintetizavam a identidade nacional.

Nos anos 1970, o regime militar privilegiou uma política cultural que buscava a codificação do controle sobre o processo cultural. Nessa direção foram estabelecidos três objetivos: o incentivo à criatividade, a difusão das criações e manifestações culturais e a preservação do patrimônio. (SANTOS, 2005) Esse último objetivo fez com que o Estado, soberano e protetor, defensor de um vasto território, ampliasse assim o seu domínio ao incorporar o papel de guardião da memória nacional. E, da mesma forma que defendia o território nacional contra invasões estrangeiras, preservava a memória contra a descaracterização. Nessa perspectiva, as políticas de salvaguarda, como alerta Ortiz (2003), passou a se confundir com a "segurança e defesa" dos bens que integram o patrimônio histórico, mas foi no âmbito da preservação do patrimônio histórico e artístico onde se encontraram conceitos e representações sobre memória nacional, identidade nacional, ou mesmo uma história dos "vencidos e esquecidos”, como aparecerá nos anos 1980. 
A política da preservação do patrimônio nacional durante os 30 anos em que Rodrigo de Melo e Franco de Andrade esteve à frente do SPHAN (1937-1967) foi marcada por duas linhas de ação: a atenção aos bens de cunho arquitetônico favoreceu, até o início da década de 1960, atividades em favor de bens culturais isolados. A preocupação era com a restauração e a preservação da "pedra e cal", de monumentos de "interesse nacional", religioso, civil ou militar: igrejas, conventos, palácios, fortes, fóruns, sobrados urbanos etc. (FONSECA, 2005) Mas a partir dos meados da década a linha de ação do tombamento oficial passou a ser marcada pela tentativa de conciliar a preservação de valores tradicionais com o desenvolvimento econômico das regiões.

Nesse momento, afirma Jocélio dos Santos (2005), a relação entre preservação e turismo interno ou externo se estreita. Essa estreita relação vai marcar as políticas nesse campo por mais de vinte anos, avançado para além do período que compreende a Ditadura Militar, deixando suas marcas nas políticas culturais das unidades da federação. Por outro lado, a possibilidade de criar uma política que vinculava cultura e turismo exigia maior atuação do órgão responsável pela política de preservação do patrimônio nacional que passou a participar da elaboração de planos-diretores aplicados aos conjuntos urbanísticos tombados e das deliberações do Conselho Nacional de Turismo e da Embratur.

Em 1970, por iniciativa do Ministério da Educação elaborou-se o Compromisso de Brasília, que estabeleceu como objetivo principal a proteção do patrimônio histórico e artístico, articulando diretrizes que instrumentalizavam a valorização do patrimônio cultural enquanto culto ao passado para a formação da consciência nacional. Aí se atendeu a um dos princípios formulados por Anderson (2005) para a edificação de uma nação enquanto comunidade imaginada, ao mesmo tempo em que, apesar das dimen- 
sões continentais do território brasileiro, tentava-se potencializar espaços enquanto elementos emblemáticos dessa brasilidade.

Para tanto, foram estabelecidas ações mais eficazes como a inclusão de matérias, nos currículos escolares, que tratassem do conhecimento e da preservação do acervo histórico e artístico, das jazidas arqueológicas e pré-históricas, das riquezas naturais e da cultura popular. O conteúdo dessas matérias era visto de modo diferenciado, no que se refere aos níveis escolares, e seguia critérios distintos para as três fases escolares. Disciplinas como Educação Moral e Cívica, História da Arte no Brasil e Estudos Brasileiros cumpriam a tarefa de agir como formadoras de uma consciência nacional. O patrimônio nacional passava a ser transmitido de modo tradicional, o ensino nas escolas, ou por meio de veículos mais modernos de comunicação como o rádio, o cinema ou a televisão. Enfim, tratava-se menos de apoiar e estimular as atividades culturais do que sugerir medidas efetivas de caráter cultural num plano eminentemente político. (SANTOS, 2005)

\section{Da narrativa da diversidade, a referência à identidade e à memória}

No processo que trouxe a sociedade brasileira ao contemporâneo, muitas correções foram implantadas no sentido da ampliação da noção de patrimônio, de memória nacional e das práticas de preservação adstritas. Como marco importante pode-se destacar o período em que Aloísio de Magalhães, a frente do Centro Nacional de Referência Cultural (CNRC), empreendeu ações no campo da preservação de patrimônio e da memória e a criação do Programa Nacional do Patrimônio Imaterial em 2000. 
Aloísio, em certa medida, tentou retomar princípios formulados por Mário de Andrade no projeto que apresentou a Gustavo Capanema para a criação do SPHAN. Mário, naquela época, estava à frente do Departamento de Cultura e Recreação da Prefeitura de São Paulo e sua participação, bem como de Lúcio Costa, na idealização e implantação da política nacional de patrimônio, foi marcada pela tentativa de, em sintonia com a interpretação modernista da cultura brasileira, incorporar uma noção de patrimônio que englobava obras de arte e arquitetônicas, assim como manuscritos, fotografias e artefatos indígenas, bem diferente da perspectiva adotada durante os anos em que Rodrigo de Melo e Franco de Andrade esteve à frente desse órgão.

Embora a Constituição Brasileira de 1988 abra espaço para ações que ampliam o leque dos bens culturais aos quais se poderá outorgar o título de patrimônio nacional - se definindo no seu Artigo 216 como "patrimônio cultural brasileiro o conjunto de bens de natureza material e imaterial que se referem à ação, à memória e à identidade dos grupos formadores da sociedade brasileira" -, ainda são recentes as ações que visam incluir os bens culturais de natureza imaterial no rol dos bens considerados como patrimônio nacional.

O único instrumento legal nesse âmbito é o Decreto $\mathrm{n}^{\circ} 3551$, assinado pelo então presidente Fernando Henrique Cardoso em agosto de 2000, instituindo o registro de bens culturais de natureza imaterial e criando o Programa Nacional do Patrimônio Imaterial. Seu Artigo $1^{\circ}$, ao instituir o registro de bens culturais de natureza imaterial que constituem o patrimônio cultural brasileiro, semelhante aos livros de tombo, estabeleceu a criação de quatro livros de registro: Livro de Registro dos Saberes, para os conhecimentos e modos de fazer enraizados no cotidiano das comunidades; Livro de Registro de Celebrações, para os rituais e festas que marcam 
a vivência coletiva do trabalho, da religiosidade, do entretenimento e outras práticas da vida social; Livro de Registros das Formas de Expressão, para as manifestações literárias, musicais, plásticas, cênicas e lúdicas e Livro de Registro dos Lugares, para mercados, feiras, santuários, praças e demais espaços onde se concentram e reproduzem práticas culturais coletivas.

Se, no início, a noção de patrimônio nacional estava intimamente ligada à necessidade de referências para a construção de uma identidade comum a um povo que compartilha o mesmo território, ao longo dessa trajetória veem-se duas novas concepções afirmarem-se. Primeiramente, a noção de que no contexto nacional existem culturas diversas e plurais, ou seja, a ideia de que a nação brasileira comporta infinidade de culturas e a noção de que a cultura congrega bens materiais e imateriais.

A ideia de povo, que dava sustentação ao projeto de identidade nacional, vê-se atravessada por uma nova concepção, uma narrativa totalizadora de povo enquanto unidade e sujeito da nação cedeu lugar à concepção de povo como grupo segmentado, formado por uma multiplicidade de culturas. Gradativamente, processos e práticas culturais começaram a ser vistos como patrimônio. A noção de patrimônio desencadeada a partir da década de 1980 passou a incorporar bens culturais que não têm necessidade de mediação de objetos. A Constituição de 1988 dá um passo fundamental ao inserir narrativas existentes fora do padrão moderno europeu como referencia à identidade nacional. Desse modo, amplia a noção de patrimônio brasileiro, incluindo a referência à identidade, à ação e à memória dos diferentes grupos formadores da sociedade brasileira.

Jean-François Lyotard (1998) já havia preconizado a passagem de uma concepção de sociedade estruturada através da constituição de grandes narrativas para etapa em que um novo modelo de 
sociabilidade estaria se articulando em torno da efervescência do local e, consequentemente, de pequenas narrativas. No entanto, um olhar mais atento pode perceber, como já fizera Steven Connor (1996), que no modelo proposto por Lyotard a produção da diversidade cultural se daria sem recorrer a princípios universais. Por outro lado, o que se pode perceber é que, a partir da década de 1980, a afirmação da heterogeneidade e da diferença, como forças centrais para a redefinição do discurso cultural, acabou por se constituir na grande narrativa que dá substância a formulação das políticas culturais no Brasil pós-abertura política. A opção por esse itinerário pôs em evidencia um campo de ação que se constituiu como possibilidade da articulação normativa da diversidade, tomada como elemento central do projeto de produção da identidade e da memória nacional, efetivados pelas políticas culturais desencadeadas em consonância com o que estabelece o texto constitucional brasileiro no Capítulo III, Seção II, Art. 215 e 216 . As políticas de patrimônio e memória passaram a se constituir no lócus ideal para a promoção da diversidade cultural brasileira. O Governo de Luiz Inácio Lula da Silva assume a tendência evidenciada pela Constituição de 1988, incorporando o Programa Monumenta à estrutura do IPHAN, diversificando as linhas de financiamento e descentralizando as atribuições para a preservação do patrimônio material, ao mesmo tempo em que as ações relativas ao PNPI são intensificadas.

O texto constitucional reflete um momento do imaginário social brasileiro que, livre das pressões nacionalistas em função do fim da ditadura, incorporou a narrativa da diversidade como elemento central das políticas culturais. A diversidade, entendida como matriz de todo processo criador, entra na pauta das políticas de preservação do patrimônio e da memória nacional. A necessidade de salvaguardar memórias particulares encontra ressonância na 
confluência de interesses e ideias que, articulando-se em torno das políticas culturais, promovem um reordenamento administrativo da esfera da cultura, culminando por dar protagonismo a grupos sociais antes excluídos do discurso social. Esses grupos, por sua vez, encontraram, nesse campo, sobretudo, nas políticas de preservação do patrimônio o lócus ideal para empreender esforços para conduzir processos identitários que veem redefinido posições e interesses diante da sociedade.

\section{Considerações finais}

Ao longo dos séculos, os grupos humanos veem evocando sentimentos que encontram nos bens culturais o seu sentido e seu lastro. Os seres humanos tentam assimilar o passado, buscando nos seus vestígios testemunhos de um tempo remoto que insiste em atualizar-se. No processo de construção social da memória edificam-se identidades e patrimônios culturais diversos. Nessa trajetória, o passado, algumas vezes, foi tomado como tesouro que se queria guardar. Imbuídas desse princípio, as políticas de produção da memória dão eco ao anseio dos seres humanos em dar resposta a uma eminente ameaça de esquecimento, se traduzindo no desejo de recuperar o passado e na vontade de memorizar e no dever de lembrar.

Em outros momentos, realçou-se a condição de determinados bens culturais assumirem interesse relevante para a afirmação da memória e da identidade cultural dos grupos humanos. Assim, um conjunto de bens materiais (prédios, praças, parques, ambiências, sítios e paisagens) e de manifestações culturais de valor significativo para um dado grupo ganham status relevante frente a outros bens, requerendo tratamento especial por parte 
da sociedade, convertendo-se em patrimônio cultural, guardião da memória e, em consequência, promotor da diversidade. As políticas nesse campo se estruturam de maneira prospectiva, apontado para o futuro. Trata-se de criar condições para que a diversidade se promova no futuro.

Se a revolução liberal trouxe consigo o fomento de um projeto pautado pela necessidade de formação de cidadãos, pela instrução e pelo culto ao Estado-Nação, fazendo com que a constituição de patrimônios culturais fosse dominada pelo seu aspecto pedagógico; na contemporaneidade a constituição de patrimônios culturais está imbricada com a constituição da diversidade cultural. No percurso iniciado com a criação do SPHAN, em 1937, até o fim da primeira década do século XXI, pode-se perceber a estreita relação das políticas nacionais de patrimônio com os projetos de produção da identidade e da memória nacional e, em muitos momentos, houve uma sinonímia entre esses três termos. Cada modelo de gestão pública idealizou um "retrato" da nação brasileira e utilizou as políticas de preservação e registro da memória nacional como referência da face da nação que interessava ao projeto político em curso. Da preservação do patrimônio de "pedra e cal" de origem colonial, desencadeado pelo SPHAN na década de 1930, à referência à identidade, à memória dos diversos grupos formadores da identidade nacional, proposta pela Constituição de 1988, vemos sobrepor-se modelos e tendências no campo do patrimônio implicados com o conjunto de interesses e forças que marcam as diversas fases da política nacional.

Passar em revisão os marcos regulatórios e as ações empreendidas no âmbito da preservação do patrimônio nacional implica entender o projeto de produção da identidade nacional em curso. Nesse sentido, apontar como se dá a produção das referências à identidade e à memória do povo brasileiro no projeto político 
implantado por Getulio Vargas em 1937, passando pela Ditadura Militar até alcançar o Brasil pós-abertura política é, ao mesmo tempo, entender como a produção da memória nacional - que desde seu nascimento vem sendo marcada por modelos de gestão que, ao longo de várias tradições autoritárias, buscaram impor uma memória particular à coletividade - está sendo ultrapassada por um modelo de gestão que tenta dar sentido e eficácia aos atos coletivos.

\section{Referências}

ALEXANDRINO, José de Melo. O conceito de bem cultural. Versão provisória do texto da lição proferida em 3 de dezembro de 2009, no Curso de PósGraduação em Direito da Cultura e do Patrimônio Cultural, organizado pelo Instituto de Ciências Jurídico-Políticas da Faculdade de Direito da Universidade de Lisboa. Disponível em: < http://www.estig.ipbeja.pt/ $\sim$ ac_direito/JMABC.pdf>. Acesso em: 27 jan. 2011.

ANDERSON, Benedict. Comunidades imaginadas: reflexões sobre a origem e a expansão do nacionalismo. Lisboa: Edições 70, 2005.

BO, J. B. Lanari. Proteção do patrimônio na Unesco: ações e significados. Brasília: Unesco, 2003.

BRASIL. Decreto n. 3551. Institui o registro de bens culturais de natureza imaterial que constituem patrimônio cultural brasileiro, cria o Programa Nacional do Patrimônio Imaterial e dá outras providencias. In: BRASIL. Ministério da Cultura. O registro do patrimônio imaterial: dossiê final das atividades da comissão e do grupo de trabalho patrimônio imaterial. Brasília: Ministério da Cultura: Instituto do Patrimônio Histórico e Artístico Nacional, 2000a.

. Carta de Brasília. In: CURY, Isabelle (Org.). Cartas patrimoniais. Rio de Janeiro: IPHAN, 2000b. p. 323-328.

. Constituição (1988). Constituição da República Federativa do Brasil. Rio de Janeiro: DP\&A, 2003.

CASTELLS, Manuel. O poder da identidade. São Paulo: Paz e Terra, 2002. (A era da informação: economia, sociedade e cultura; v. 2)

CONNOR, Steven. Cultura pós-moderna: introdução às teorias do contemporâneo. São Paulo: Loyola, 1996. 
CUNHA, Danilo Fontenele Sampaio. Patrimônio cultural: proteção legal e constitucional. Rio de Janeiro: Letra Legal, 2004.

FONSECA, M. C. L. O patrimônio em processo: trajetória da política federal de preservação no Brasil. Rio de Janeiro: Ed. UFRJ: IPHAN, 2005.

LYOTARD, Jean-François. A condição pós-moderna. 5. ed. Rio de Janeiro: José Olympio, 1998.

MENEZES, José Newton Coelho. Memória e historicidade dos lugares: reflexão sobre a interpretação do patrimônio cultural das cidades. In:

AZEVEDO, Flávia Lemos Mota de; CATÃO, Leandro Pena; PIRES, João Ricardo (Org.). Cidadania, memória e patrimônio: as dimensões do museu no cenário atual. Belo Horizonte: Crisálida, 2009.

ORTIZ, Renato. Cultura brasileira e identidade nacional. São Paulo: Brasiliense, 2003.

POULOT, Dominique. Uma história do patrimônio no ocidente. São Paulo: Estação Liberdade, 2009.

RODRIGUES, Maria da Paz de Jesus. Caminhos da preservação: políticas, patrimônio material e reflexos na dinâmica social e urbana de Cachoeira-Ba. Dissertação (Mestrado em Cultura, Memória e Desenvolvimento Regional) Departamento de Ciências Humanas - Campus V - Universidade do Estado da Bahia, 2010.

SANTOS, Adalberto Silva. Tradições populares e resistências culturais: políticas públicas em perspectiva comprada. Salvador: EDUFBA, 2011.

SANTOS, Jocélio Teles. O poder da cultura e a cultura no poder: a disputa simbólica da herança cultural negra no Brasil. Salvador: EDUFBA, 2005.

SEVERINO, José Roberto; SANTOS, Adalberto Silva. Patrimônio cultural e memória. Políticas Culturais em Revista, v. 1, n. 3, p. 1-4, 2010. Disponível em: www.politicasculturaisemrevista.ufba.br. Acesso em 30 de janeiro de 2011.

UNESCO. Convenção sobre a salvaguarda do patrimônio mundial, cultural e natural. In: CURY, Isabelle (Org.). Cartas patrimoniais. Rio de Janeiro: IPHAN, 2000. p. 77-94.

. Recomendação sobre medidas destinadas a proibir e impedir a exportação, a importação e a transferência de propriedade ilícita de bens culturais. In: CURY, Isabelle (Org.). Cartas patrimoniais. Rio de Janeiro: IPHAN, 2000. p. 97-104.

. Convenção para a salvaguarda do patrimônio cultural imaterial. Disponível em: <www.unesco.org>. Acesso em: 05 de fevereiro de 2009.

. Convenção sobre a proteção e promoção da diversidade das expressões culturais. Disponível em: < http://unesdoc.unesco.org/images $>$. Acesso em: 30 jan. 2011. 
VELOSO, Mariza Motta Santos. Nasce a Academia SPHAN. Revista do Patrimônio Histórico e Artístico Nacional. Rio de Janeiro, v. 1, ago. 1996.

88 Patrimônio e memória: da imposição de identidades... 